\title{
Reversal of olanzapine-induced weight gain in a patient with schizophrenia by switching to asenapine: a case report
}

This article was published in the following Dove Press journal:

Neuropsychiatric Disease and Treatment

Number of times this article has been viewed

\section{Kosuke Okazaki \\ Kazuhiko Yamamuro \\ Toshifumi Kishimoto \\ Department of Psychiatry, Nara Medical University School of \\ Medicine, Kashihara, Japan}

Correspondence: Kazuhiko Yamamuro Department of Psychiatry, Nara Medical University School of Medicine, 840 Shijocho Kashihara, Nara 634-852I, Japan

Tel +8I 74422305 I

Fax +8I 744223854

Email muro@naramed-u.ac.jp
Aims: Antipsychotics are effective for treating schizophrenia, but atypical antipsychotics can cause several adverse side effects including weight gain, hyperprolactinemia, and extrapyramidal symptoms. Moreover, weight gain increases the risk of metabolic diseases.

Methods: We treated a case of olanzapine-induced weight gain in a 41-year-old man with schizophrenia by switching his medication from olanzapine to asenapine.

Results: The weight gain improved after switching the medication, from 80.3 to $75.0 \mathrm{~kg}$, a weight loss of $6.6 \%$, and there was no significant worsening of psychological symptoms or other adverse effects.

Conclusions: Asenapine might be effective for treating patients with schizophrenia who experience olanzapine-induced weight gain.

Keywords: olanzapine, weight gain, schizophrenia, asenapine

\section{Introduction}

Schizophrenia, which affects $\sim 1 \%$ of the global population, is a psychotic disorder characterized by positive symptoms, negative symptoms, and progressive cognitive deficits. ${ }^{1}$ It chronically impacts social relations, daily living, and vocational function, ${ }^{2,3}$ and can reduce life expectancy by up to 20 years. ${ }^{4}$

Schizophrenia is mainly treated with antipsychotics, ${ }^{5}$ which block dopaminergic, histaminergic, serotonergic, cholinergic, and alpha-adrenergic receptors. Their strong affinities for these receptors affect both positive and negative symptoms. Atypical antipsychotics (AAPs) are effective for treating schizophrenia and have fewer side effects than typical antipsychotics, ${ }^{6}$ but they can still cause extrapyramidal symptoms, ${ }^{7}$ hyperprolactinemia,${ }^{8}$ sedation, ${ }^{9}$ and weight gain. ${ }^{7,8}$ These side effects can lead to patient nonadherence with treatment. ${ }^{7}$ Weight gain in particular is associated with metabolic complications such as lipid abnormalities, glucose intolerance, and hypertension. ${ }^{10}$ Recent guidelines, including those from the British Association for Psychopharmacology, recommend switching to a low-weight gain alternative antipsychotic if olanzapine-induced weight gain is excessive. ${ }^{11}$ Olanzapine is an AAP that is classified as a multi-acting receptor-targeted antipsychotic agent (MARTA) and carries the second highest risk of weight gain among AAPs after clozapine. ${ }^{12}$ Asenapine is another MARTA AAP and was approved for schizophrenia in 2009. Previous studies have shown that it carries a lower risk of weight gain than olanzapine. ${ }^{12,13}$ 


\section{Case presentation}

A 41-year-old man with schizophrenia began experiencing auditory hallucinations when he was 19 years old, but had only been prescribed antipsychotics after being hospitalized for worsening psychosis when he was 29 years old. After the hospitalization, he was referred to our hospital, but he did not consistently adhere to treatment, so his psychosis exhibited cyclical remissions and relapses. When he was 41 years old, auditory hallucinations and delusions of persecution caused him to refuse food despite being prescribed quetiapine, so he was again referred to our hospital. He weighed $56 \mathrm{~kg}$ and had a body mass index (BMI) of $16.3 \mathrm{~kg} / \mathrm{m}^{2}$. He did not have a history of other comorbid medical illness.

The patient was diagnosed with schizophrenia according to the criteria in the Diagnostic and Statistical Manual of Mental Disorders, 5th Edition. His symptoms were assessed using the Japanese version of the Positive and Negative Syndrome Scale (PANSS), in which higher scores indicate greater severity according to the 7-point Likert scale. Subscale scores were calculated using small sets of variables from the three PANSS domains: positive, negative, and general psychopathological symptoms. Higher PANSS scores indicate more severe psychotic symptoms. He obtained a PANSS score of 159 . He was continuously prescribed quetiapine at a dose starting at $400 \mathrm{mg} /$ day and increasing to $600 \mathrm{mg} / \mathrm{day}$, but this failed to ameliorate his hallucinations and delusions; while on quetiapine his PANSS score was 150. After 4 weeks, his prescription was, therefore, switched to aripiprazole at a dose that increased to $30 \mathrm{mg} /$ day, but his PANSS score was still 139. His prescription was then switched to olanzapine at a dose that increased to $20 \mathrm{mg} /$ day over 2 weeks, and he showed gradual improvement in his positive symptoms. After 3 months of olanzapine at $20 \mathrm{mg}$ /day, his PANSS score was 68 . Although he experienced markedly reduced psychosis, olanzapine-induced overeating increased his weight to $80.3 \mathrm{~kg}$ and his BMI to $23.5 \mathrm{~kg} / \mathrm{m}^{2}$. At this point, he did not appear to have any physical illness such as diabetes, dyslipidemia, or hypertension. We, therefore, tapered his olanzapine dose over 2 weeks until discontinuation while giving him asenapine at a dose that increased to $20 \mathrm{mg} /$ day. His overeating reduced within a week after the tapering had ended without exacerbation of psychosis. After a month of asenapine at $20 \mathrm{mg} /$ day, his weight decreased to $78.0 \mathrm{~kg}$ with BMI of $22.7 \mathrm{~kg} / \mathrm{m}^{2}$, and his PANSS score was 66 , indicating no worsening of psychosis. Over the following 1 year, the dose was maintained, his weight gain did not recur $(75.0 \mathrm{~kg}$ with BMI of $21.8 \mathrm{~kg} / \mathrm{m}^{2}$ ), and he had few side effects. Importantly, he never received other interventions that could affect weight loss during the observation period, such as dietary counseling or changes in diet and exercise. The patient was also taking benzodiazepines, but the quantity and types of benzodiazepines did not change during this period.

\section{Discussion}

To the best of our knowledge, this case represents the first evidence that asenapine is an effective and well-tolerated therapy for improving olanzapine-induced weight gain without exacerbating psychotic symptoms.

AAPs increase the risk of weight gain ${ }^{14}$ by blocking 5- $\mathrm{HT}_{2 \mathrm{C}}$ serotonin receptors and $\mathrm{H}_{1}$ histamine receptors, with olanzapine carrying a particularly high risk. ${ }^{12}$ This causes many metabolic abnormalities, including increased appetite ${ }^{15}$ and elevated blood levels of glucose ${ }^{16}$ fasting triglycerides, and leptin, ${ }^{17}$ but these effects are smaller with asenapine treatment than with olanzapine treatment. ${ }^{13,18}$ The difference might result from asenapine's unique receptor-binding profile, which includes antagonism of dopamine receptors, serotonin receptors, and adrenergic receptors. ${ }^{19-21}$ Unlike olanzapine, asenapine has moderate histamine receptor affinity and no appreciable muscarinic receptor affinity. ${ }^{22}$ In rats, treatment with asenapine for 5 weeks decreases weight and triglyceride levels. ${ }^{23}$ In short- and long-term clinical studies, asenapine was well tolerated and carried a lower risk of weight gain and metabolic abnormalities than olanzapine in adult patients with schizophrenia or bipolar I disorder ${ }^{18,24}$ Further, Bak et al have shown that a significant proportion of patients may experience $>7 \%$ weight loss after starting asenapine without showing a duration response pattern. ${ }^{25}$ Asenapine may, therefore, be an effective option for treating weight gain induced by other AAPs in patients with schizophrenia.

In a meta-analysis comparing antipsychotics, asenapine was no less effective than olanzapine for acute schizophrenia. ${ }^{26}$ Patients with schizophrenia can, therefore, transition from olanzapine to asenapine without significant exacerbation of positive or negative symptoms. However, it is important that the olanzapine dose be tapered because rapid withdrawal may trigger cholinergic withdrawal syndromes, such as agitation, headache, insomnia, anxiousness, diarrhea, abdominal pain, and queasiness. ${ }^{27} \mathrm{~A}$ previous report has shown that in Asian populations, a BMI of 23 or higher indicates a greater health risk. ${ }^{28}$ Although the patient's BMI was well within the normal range while on olanzapine, it is important to control his weight considering the potential for metabolic comorbidities that could arise in the future.

In this case report, only a $6.6 \%$ weight loss was achieved with asenapine, where weight gain or loss must be at least $7 \%$ to be clinically meaningful. However, maintaining the weight loss is more important than reducing weight temporarily, even if 
the weight loss is $>7 \%$. This case suggests that asenapine is an effective and well-tolerated treatment for antipsychotic-induced metabolic abnormalities in patients with schizophrenia.

\section{Conclusion}

This case suggests that asenapine might be an efficacious and well-tolerated treatment for olanzapine-induced weight gain in patients with schizophrenia. Further studies with larger sample sizes are needed to validate the apparent efficacy, safety, and tolerability of asenapine in this application.

\section{Acknowledgments}

We would like to thank the patient and his family for their cooperation. As we encountered this case during regular clinical practice, the need for ethics approval and consent was waived. We obtained written informed consent for the publication of this case report from the patient. Data sharing was not applicable to this article as no datasets were generated or analyzed during the current study.

This case report did not receive any specific grant from funding agencies in the public, commercial, or not-for-profit sectors.

\section{Author contributions}

$\mathrm{KO}$ collected data and wrote the first draft of the manuscript. KY and TK supervised the project, were critically involved in its design, and assisted in editing the final manuscript. All authors contributed toward data analysis, drafting and revising the paper and agree to be accountable for all aspects of the work.

\section{Disclosure}

The authors report no conflicts of interest in this work.

\section{References}

1. Association AP. Diagnostic and Statistical Manual of Mental Disorders-5. 5th ed. Washing, DC: APA; 2013.

2. Tiihonen J, Haukka J, Taylor M, Haddad PM, Patel MX, Korhonen P. A nationwide cohort study of oral and depot antipsychotics after first hospitalization for schizophrenia. Am J Psychiatry. 2011;168(6):603-609.

3. Jakubovski E, Carlson JP, Bloch MH. Prognostic subgroups for remission, response, and treatment continuation in the Clinical Antipsychotic Trials of Intervention Effectiveness (CATIE) trial. J Clin Psychiatry. 2015;76(11):1535-1545.

4. Lawrence D, Hancock KJ, Kisely S. The gap in life expectancy from preventable physical illness in psychiatric patients in Western Australia: retrospective analysis of population based registers. BMJ. 2013;346:f2539.

5. van Os J, Kapur S. Schizophrenia. Lancet. 2009;374(9690):635-645.

6. Bruijnzeel D, Suryadevara U, Tandon R. Antipsychotic treatment of schizophrenia: an update. Asian J Psychiatr. 2014;11:3-7.

7. Kane JM. Addressing side effects from antipsychotic treatment in schizophrenia. J Clin Psychiatr. 2011;72(2):e07.

8. De Hert M, Yu W, Detraux J, Sweers K, van Winkel R, Correll CU. Body weight and metabolic adverse effects of asenapine, iloperidone, lurasidone and paliperidone in the treatment of schizophrenia and bipolar disorder: a systematic review and exploratory meta-analysis. CNS Drugs. 2012;26(9):733-759.
9. Citrome L. Activating and sedating adverse effects of second-generation antipsychotics in the treatment of schizophrenia and major depressive disorder: absolute risk increase and number needed to harm. $J$ Clin Psychopharmacol. 2017;37(2):138-147.

10. Mackin P, Bishop D, Watkinson H, Gallagher P, Ferrier IN. Metabolic disease and cardiovascular risk in people treated with antipsychotics in the community. Br J Psychiatry. 2007;191:23-29.

11. Cooper SJ, Reynolds GP, Barnes T, et al. BAP guidelines on the management of weight gain, metabolic disturbances and cardiovascular risk associated with psychosis and antipsychotic drug treatment. J Psychopharmacol. 2016;30(8):717-748.

12. Leucht S, Cipriani A, Spineli L, et al. Comparative efficacy and tolerability of 15 antipsychotic drugs in schizophrenia: a multiple-treatments meta-analysis. Lancet. 2013;382(9896):951-962.

13. Kemp DE, Zhao J, Cazorla P, et al. Weight change and metabolic effects of asenapine in patients with schizophrenia and bipolar disorder. J Clin Psychiatry. 2014;75(3):238-245.

14. Megna JL, Schwartz TL, Siddiqui UA, Herrera Rojas M. Obesity in adults with serious and persistent mental illness: a review of postulated mechanisms and current interventions. Ann Clin Psychiatry. 2011; 23(2):131-140.

15. Fountaine RJ, Taylor AE, Mancuso JP, et al. Increased food intake and energy expenditure following administration of olanzapine to healthy men. Obesity (Silver Spring). 2010;18(8):1646-1651.

16. Newcomer JW. Second-generation (atypical) antipsychotics and metabolic effects: a comprehensive literature review. CNS Drugs. 2005; 19(Suppl 1):1-93.

17. Albaugh VL, Singareddy R, Mauger D, Lynch CJ. A double blind, placebocontrolled, randomized crossover study of the acute metabolic effects of olanzapine in healthy volunteers. PLoS One. 2011;6(8):e22662.

18. Schoemaker J, Stet L, Vrijland P, Naber D, Panagides J, Emsley R. Long-term efficacy and safety of asenapine or olanzapine in patients with schizophrenia or schizoaffective disorder: an extension study. Pharmacopsychiatry. 2012;45(5):196-203.

19. Szegedi A, Zhao J, van Willigenburg A, Nations KR, Mackle M, Panagides J. Effects of asenapine on depressive symptoms in patients with bipolar I disorder experiencing acute manic or mixed episodes: a post hoc analysis of two 3-week clinical trials. BMC Psychiatry. 2011; 11:101.

20. Azorin JM, Sapin C, Weiller E. Effect of asenapine on manic and depressive symptoms in bipolar I patients with mixed episodes: results from post hoc analyses. J Affect Disord. 2013;145(1):62-69.

21. Young AH, Altamura AC, Gonzalez-Pinto AM, Millet B, Wiedemann K. Use of asenapine in clinical practice for the management of bipolar mania. J Psychopharmacol. 2013;27(4 Suppl):3-13.

22. Shahid M, Walker GB, Zorn SH, Wong EH. Asenapine: a novel psychopharmacologic agent with a unique human receptor signature. J Psychopharmacol. 2009;23(1):65-73.

23. de Brito RB, Ghedini PC. Treatment by asenapine for 5 weeks decreases weight and triglycerides levels of Wistar rats. Schizophr Res. 2014;154(1-3):124-125.

24. Buchanan RW, Panagides J, Zhao J, et al. Asenapine versus olanzapine in people with persistent negative symptoms of schizophrenia. J Clin Psychopharmacol. 2012;32(1):36-45.

25. Bak M, Fransen A, Janssen J, van Os J, Drukker M. Almost all antipsychotics result in weight gain: a meta-analysis. PLoS One. 2014; 9(4): 94112.

26. Szegedi A, Verweij P, van Duijnhoven W, Mackle M, Cazorla P, Fennema H. Meta-analyses of the efficacy of asenapine for acute schizophrenia: comparisons with placebo and other antipsychotics. J Clin Psychiatry. 2012;73(12):1533-1540.

27. Cerovecki A, Musil R, Klimke A, et al. Withdrawal symptoms and rebound syndromes associated with switching and discontinuing atypical antipsychotics: theoretical background and practical recommendations. CNS Drugs. 2013;27(7):545-572.

28. WHO Expert Consultation. Appropriate body-mass index for Asian populations and its implications for policy and intervention strategies. Lancet. 2004;363(9403):157-163. 


\section{Publish your work in this journal}

Neuropsychiatric Disease and Treatment is an international, peerreviewed journal of clinical therapeutics and pharmacology focusing on concise rapid reporting of clinical or pre-clinical studies on a range of neuropsychiatric and neurological disorders. This journal is indexed on PubMed Central, the 'PsycINFO' database and CAS,

and is the official journal of The International Neuropsychiatric Association (INA). The manuscript management system is completely online and includes a very quick and fair peer-review system, which is all easy to use. Visit http://www.dovepress.com/testimonials.php to read real quotes from published authors.

Submit your manuscript here: http://www.dovepress.com/neuropsychiatric-disease-and-treatment-journal 